\title{
EFFICACY AND SAFETY EVALUATION OF RITUXIMAB IN PATIENTS WITH REFRACTORY LUPUS NEPHRITIS IN A TERTIARY UNIVERSITY HOSPITAL: REPORT OF CASE SERIES
}

Sanna Paula Pires Mariano Campos ${ }^{1}$, Thyago Talles de Almeida Santana ${ }^{1}$, Gabriela Almeida Barbosa ${ }^{1}$, Robson Antônio Gonçalves ${ }^{1}$, Danielle Christinne Soares Egypto de Brito ${ }^{1}$, Ana Karla Guedes de Melo ${ }^{1}$, Alessandra De Sousa Braz ${ }^{1}$, Eutilia Andrade Medeiros Freire ${ }^{1}$

1.Hospital Universitário Lauro Wanderley, João Pessoa (PB), Brazil.

*Corresponding author: sanninhapaula@hotmail.com

\section{BACKGROUND}

Lupus nephritis is one of the major complications in the systemic lupus erythematosus (SLE), whereas it is the main factor of morbimortality. Depletion of B lymphocytes has been a new therapeutic option for patients who are refractory to conventional treatments schemes.

\section{MATERIALS AND METHODS}

Retrospective study, with report of seven patients diagnosed with Lupus by the 2012 SLICC criteria, who took rituximab for nephritis refractory to first-line treatment. Patients with lupus and nephritis were excluded due to other causes (medicines, infection, diabetes mellitus, renal artery or vein thrombosis). The clinical-laboratorial and immunological profiles of the patients in addition to their evolution after using rituximab were assessed.

\section{RESULTS}

Seven patients around 25 years-old, being six women (85.7\%) and one man (14.28\%) were analyzed. There wasn't any reaction during the administration of the medicine, nevertheless one patient was hospitalized after the first cycle due to infection that might have been secondary to the immunodeficiency caused by the drug. Concerning the treatment, one patient (14.28\%) had partial remission, three patients (42.85\%) obtained total remission and three patients (42.85\%) did not show any response. Among the patients who responded to the treatment, one of them had complete remission in the first dose and another one had a history of difficulty in adhering to first-line conventional treatment and rituximab permitted a proper adhesion to the treatment. Among the patients who did not respond to treatment, one of them evolved with chronic renal failure, although he presented poor prognosis, such as being a male, besides being diagnosed with lupus as a teenager and class 4 lupus nephritis in the renal biopsy.

\section{CONCLUSION}

The results of these cases demonstrate that $60 \%$ of patients had reached remission, thus this outcome is coherent with the literature and it proves that rituximab is a good therapeutic option for the refractory cases of nephritis. Nonetheless new studies must be conducted with a larger number of patients. 